\title{
Obstetric Care among Refugees: The Complex Interplay of Barriers to Care, Culture, Health Resources and the Healthcare Infrastructure of Host Countries
}

\author{
Helai Hesham', Marghalara Hesham², Annekathryn Goodman ${ }^{3 *}$ \\ ${ }^{1}$ Department of Obstetrics and Gynecology, Harvard Medical School, Massachusetts General Hospital, Boston, MA, USA \\ ${ }^{2}$ Kabul Medical College, Kabul, Afghanistan \\ ${ }^{3}$ Department of Obstetrics, Gynecology, Reproductive Biology, Harvard Medical School, Division of Gynecological Oncology, \\ Massachusetts General Hospital, MGH Global Disaster Response, Boston, MA, USA \\ Email:HHESHAM@mgh.harvard.edu, MarghalaraSH@gmail.com, *agoodman@mgh.harvard.edu
}

How to cite this paper: Hesham, H., Hesham, M. and Goodman, A. (2019) Obstetric Care among Refugees: The Complex Interplay of Barriers to Care, Culture, Health Resources and the Healthcare Infrastructure of Host Countries. Open Journal of Obstetrics and Gynecology, 9, 170-185. https://doi.org/10.4236/ojog.2019.92018

Received: January 8, 2019

Accepted: February 8, 2019

Published: February 11, 2019

Copyright $\odot 2019$ by author(s) and Scientific Research Publishing Inc. This work is licensed under the Creative Commons Attribution International License (CC BY 4.0).

http://creativecommons.org/licenses/by/4.0/

(c) () Open Access

\begin{abstract}
There is a worldwide increase in the rate of caesarean sections. With recent migration patterns and the influx of refugees into high-income countries, migrants and refugees are also subjected to the increase in caesarean section rates. This article explores known information about the obstetrical experiences of refugee and displaced women. Pregnancy care varies depending on the location of the displaced women. Obstetrical care in refugee centers in Greece is examined as an example of the overall challenges facing European countries as they juggle the influx of refugees. Challenges to obstetrical care include physician shortage and the ongoing economic crisis in Greece. Refugees are some of the world's most vulnerable populations and overall their obstetrical outcomes are worse than women of the host communities. Providers in refugee centers must be supported and educated in best obstetrical practices including labor management and a judicious use of caesarean deliveries. Increased outreach and training of maternal health worker can improve reproductive healthcare for refugees in non-camp environments.
\end{abstract}

\section{Keywords}

Refugee, Obstetrical Care, Perinatal Health, Refugee Camp,

Caesarean Section, Displaced Populations

\section{Background}

The UN reports a huge increase in displaced peoples and refugees in 2018. Glo- 
bally, the forcibly displaced population increased in 2017 by 2.9 million. By the end of the year, 68.5 million individuals were forcibly displaced worldwide as a result of persecution, conflict, or generalized violence. As a result, the world's forcibly displaced population remains at a record high [1]. Many of the refugees are women of childbearing age. Medical needs of refugees are complex and include reproductive health, mental health, treatment of injuries and both communicable and noncommunicable diseases [2]. Refugee camps and communities hosting refugee communities have faced the challenge of delivering obstetrical care with limited resources. Labor management and safe deliveries require trained attendants and there can be many barriers to receiving this care. This can lead paradoxically to increasing cesarean section rates where there are few resources for labor management within refugee camps or at hospital facilities while in contrast there is a lack of resources and surgical interventions among non-camp refugees and internally displaced persons.

Cesarean sections (CSs) are the most commonly performed surgical procedures in the world today [3]. The World Health Organization (WHO) suggests that the optimal CS rates in developed countries exist somewhere between $10 \%$ and 15\% [4]. There has been a worldwide increase in cesarean section (CS) rates. According to the latest data from 150 countries, currently $18.6 \%$ of all births occur by CS, ranging from 6\% (Africa) to $40.5 \%$ (Latin America) in the least and most developed regions, respectively [4]. CS rates in the United States have remained stable at slightly over $32 \%$ over the past 10 years despite nationwide interventions to reduce rates [5]. With new migration patterns and the influx of refugees in recent years into Australia, Europe, and North America, migrants and refugees may experience increased caesarean section rates.

This review examines current knowledge of obstetrical care for refugee women in selected settings of refugee camps, non-camp populations, and internally displaced groups. The case of Greece is examined as a case study of increased cesarean section rates among refugee camp women.

\section{Methods}

A search for peer-reviewed papers via the Ovid MEDLINE database, followed by a PubMed search to pick up more recent papers not currently indexed was used. In addition, references for included papers were crosschecked to ensure that all relevant literature was identified and included. A combination of terms describing Refugee, Obstetrical care, perinatal health, Refugee Camp, Caesarean Section, Displaced Populations was used in the search.

\section{Displaced Populations}

The health of displaced women is a serious concern. In a crisis situation, one in five women of childbearing age are pregnant [6]. Globally 15 percent of pregnancies will result in a life-threatening complication, and the risks for such complications are compounded in places that have been hit by conflict or disas- 
ter [7]. It is essential that women and newborns receive the care they need, even in such settings.

Refugees can be internally displaced but remaining in their own country or have crossed national lines to be externally displaced. Much of the refugee community has fled man-made conflict. Refugees can live within confined camp spaces or among the host community. The UNHCR defines refugees who have left their home countries by three discrete terms: asylum seekers, refugees, and migrants [8]. Asylum seekers, whose refugee status has not yet been determined, seek international protection. Refugees, whose asylum application has been accepted, have been forced to leave their country to escape war, persecution, or natural disaster. Migrants leave their country for economic reasons to seek a better life.

There are variations in healthcare delivery between the two groups of refugees living in camp versus non-camp settings. Current statistics show that there are 25.4 million refugees with 40.0 million internally displaced people, 19.9 million refugees under UNHCR's mandate, 5.4 million Palestine refugees under UNRWA's mandate, and 3.1 million asylum-seekers [8]. Reproductive health services are more likely to be present within camps and are largely absent for non-camp populations [9]. Countries that have recently experienced armed conflict have higher rates of maternal mortality [10]. There is a two-fold increased risk of maternal mortality amongst migrant women in Western European countries compared to European nationals [11].

General Challenges to obtaining quality obstetrical services include lack of funds, inadequate infrastructure, shortage of essential medicines and equipment. Other barriers to care include shortage of trained staff, high turnover of staff, and gaps in communication and transportation systems [12].

\section{Specific Refugee Crises and Maternal Health}

A 2015 systematic review of reproductive health programs in humanitarian settings identified reports on thirty worldwide programs: 25 from Africa, two in Haiti, and six in Asia [13]. Women with refugee backgrounds in general have greater risks of adverse pregnancy outcomes [14]. Overall, challenges included lack of data in delivery registers and a shortage of trained personnel but the review demonstrated that reproductive health programs can be set up in challenging environments and will be utilized [15]. A larger review of all current publications on perinatal health identified adverse pregnancy outcomes among asylum seekers and refugees as a double burden of inequality-as a foreigner and as a woman [16].

\subsection{Africa}

Women displaced from African countries with humanitarian crises have increased risks of stillbirths, perinatal mortality, and increased cesarean section rates [17]. A comparison study of refugees from Africa compared to immigrants 
from non-conflict African countries living in Australia revealed poorer general health and social disadvantage among refugees [18]. While this study did not show a higher cesarean section rate among refugees, other research has shown a higher incidence of cesarean section among African, East African, and Somali migrants who have found refuge in European countries [17] [19] [20]. For refugee women living in Africa, reproductive healthcare barriers lead to less care overall. These communities do not live within refugee camps per se but rather among the host population. Table 1 summarizes barriers to delivery of emergency obstetric and neonatal care in the post conflict communities of Burundi and North Uganda [21].

In Burundi, female life expectancy in 2012 was 57 years. Maternal mortality ratio (MMR) of 740 per 100,000 live births and the neonatal mortality rate was 36 per 1000 live births [22]. In 2000, the Mtendeli camp for Burundi refugees, in Tanzania, neonatal and maternal deaths accounted for $16 \%$ of all deaths [23]. Those with poor pregnancy outcome were more likely to report prior high socioeconomic status, having a first or second pregnancy, and having three or more episodes of malaria during pregnancy.

A qualitative study of emergency obstetric and neonatal care (EmONC) services in 2015 found a lack of basic medications and equipment in many facilities and the insecurity and danger of the region led in inadequate communication and referrals [21]. EmONC services were available at only $1.8 \%$ of health facilities.

In North Uganda, MMR is 360 per 100,000 live births and neonatal mortality is 23 per 1000 live births [22]. The quality of EmONC was poor and basic supplies such as blood pressure cuffs and uterotonics were unavailable in some facilities [21].

Table 1. Barriers to emergency obstetrics and neonatal care [21].

\begin{tabular}{|c|c|}
\hline \multicolumn{2}{|r|}{ Human Resources } \\
\hline Resources & Challenges and Barriers \\
\hline \multicolumn{2}{|c|}{ Human Resources } \\
\hline & Shortage of trained personnel \\
\hline & High personnel turnover \\
\hline & High work load and burn-out \\
\hline & Poor level of coordination \\
\hline \multicolumn{2}{|l|}{ Institutional } \\
\hline & Lack of essential medications and equipment \\
\hline & Poor data and monitoring \\
\hline \multicolumn{2}{|l|}{ Systemic } \\
\hline & Poorly operational ambulance services \\
\hline & Inefficient drug supply system \\
\hline & Poor allocation of scarce resource \\
\hline & Limited training curriculum \\
\hline
\end{tabular}




\subsection{Asia}

Asia, like Africa, has large displaced populations. Women born in Afghanistan, Bhutan, Iraq, and Myanmar had poorer general maternal health. These women had increased risks of lower engagement in prenatal care, and post-term birth [24].

Estimated at 3.6 million, Afghans are the largest population of refugees in the world [25]. There are 2.5 million registered refugees and they comprise the largest refugee population in Asia and the second largest in the world. Maternal deaths account for a substantial burden of mortality among Afghan refugee women of reproductive age in Pakistan. Compared with women who died of non-maternal causes, women dying from maternal causes had a greater number of barriers to health care and their deaths were more likely to be preventable [26].

The International Rescue Committee (IRC) reported on their work to reduce maternal mortality among Afghan refugees in Hangu district of Pakistan [27]. Strategies included using health information and community knowledge of danger signs of pregnancy and improving access to emergency obstetric care (EmOC). With these interventions maternal mortality ratio among Afghan refugees in the area improved from 291 per 100,000 live births in 2000 to 102 per 100,000 live births in 2004. The proportion of refugee births attended by skilled staff increased from 5\% in 1996 to $67 \%$ in 2007.

The refugee crisis from Burma/Myanmar is ongoing and growing [28].

For internally displaced populations in the conflict zones of Myanmar, reproductive health services are limited. A 2010 report evaluating the intervention of training community maternal health workers (MHWs) notes that women largely delivered at home (82.9\%), or at one of the mobile locations $(12.0 \%)$ set up by the MHWs and/or the ethnic health committees in the target communities. Hospital delivery occurred for only $4.2 \%$ of displaced women [29].

\section{Mode of Obstetrical Delivery}

In the large population displacements in the West African conflicts of the 1990s refugee health aid included an increase in surgical obstetrical interventions [30]. However cesarean rates in refugee camps vary by country. Generally, most deliveries in Cameroon occurred in health facilities (66\%), but women in the refugee zone were more likely to be delivered out of health facilities (61.6\% vs. $32.1 \%$ ). Though caesarean delivery rate was less than $5 \%$ for the whole country in 2011, it was significantly lower in the refugee zone ( $4.4 \%$ vs. $2 \%)$ [31].

Mode of delivery has been analyzed by comparing refugee and migrant women to the obstetrical care received by women of the host communities. One review found the operative modes of delivery were higher among migrant women in western industrialized countries [32]. Another systematic review showed differences in caesarean section rates by place of the refugee/migrant woman's origin and the host country [33]. In particular there were higher overall caesarean rates for Sub-Saharan African, Somali and South Asian women; higher emergency CS rates for North African/West Asian and Latin American women; and 
lower overall CS rates for Eastern European and Vietnamese women. Possible risk factors for cesarean sections included language barriers, poverty, poor maternal health, gestational diabetes, fetal-pelvic disproportion, and inadequate prenatal care. Language barriers are a known risk factor for difficulty accessing medical services and suboptimal care [34].

\section{The Case of Greece}

Between 2015 and 2016, 2.68 million refugees fled to Europe with over 1 million of them entering through Greece [8] [35]. Greece currently hosts 57,000 refugees on the mainland and reception centers on five islands (Lesvos, Chios, Kos, Samos, Leros) [36]. This massive demographic and social change to Greece's country occurs at a time of severe economic crisis [37]. This has led to significant healthcare challenges for Greece's own citizens [38] [39] [40]. Table 2 compares numbers of healthcare personnel in Greece versus Germany per 100,000 population. The main difference is the increased number of nurses in Germany compared to Greece.

With the political crises that are ongoing in countries such as Syria, refugee and migrant populations are traveling to countries such as Greece, which may have caesarean section rates as high as $60 \%-70 \%$ [41]. Historically, Greece has faced the same increase in cesarean sections rates as other Western countries with the overall cesarean section rate increasing progressively from $13.8 \%$ (years 1977-1983) to $29.9 \%$ (years 1994-2000) [42]. More recently the CS rate has been reported as $28.8 \%$ at one teaching institution in 2015 [43]. However, one report notes rates of caesarean sections that vary from $65 \%$ in private clinics to $45 \%$ in public hospitals [44]. Data on caesarean section rates for refugees has been anecdotally reported as high as $60 \%$ [45].

The proportion of refugee women is at its highest in Greece; in 2016, they composed $21 \%$ of those entering Greece by sea, compared to $13 \%$ in Italy and $8 \%$ in Spain [46]. Under humanitarian clauses in Greece, maternity care is legally classified as "urgent care". Pregnant woman may access healthcare through Law 4386/2016 in Greece, which allows free maternity care for all women of regardless of finances or political or legal status [46].

There have been narratives of refugee women who believe that they have been forced to have caesarean sections without consent, have had limited postoperative care within the hospitals, or have had care without appropriate communication due to unavailability of interpreters [47].

Table 2. Health resources per country [50].

\begin{tabular}{ccc}
\hline Healthcare professionals per 100,000 population & Germany & Greece \\
\hline Doctors & 405 & 619 \\
Nurses & 1296 & 355 \\
Midwives & 24 & 23 \\
Obstetrician Gynecologists & 20 & 26 \\
Health Expenditure \% GDP & 11.3 & 9.8 \\
\hline
\end{tabular}


Health care for refugee populations in Greece reflects a large challenge in Greece because of reduced funding and availability of healthcare providers. There are already known shortages at public hospitals within Greece. Ever since the economic crisis of 2010, nearly 18,000 Greek physicians have left Greece for work in other countries [48]. In addition, in 2011, there were reports of $40 \%$ reduction in budgets to public hospitals [49]. With such shortages, delivery of obstetric care and all medical care is stretched thin. The remaining physicians in public hospitals have emotional exhaustion and burnout [49].

Informed consent for caesarean sections and other healthcare may be challenged in a fragile healthcare system and with refugees who do not speak the host country language. When the Hellenic Action for Human Rights interviewed nearly twenty-two mothers who had obstetric care in Greece while living in refugee camps in 2016, nearly $100 \%$ of participants reported that they do not give informed consent for antenatal and perinatal care. Nearly $60 \%$ of participants had caesarean sections, and although they reported that they did not feel "bullied" into the surgeries, they did state that they did not know why it was occurring. The report also noted one woman had a caesarean hysterectomy and still does not know the reason as to why it was required [45].

Proper consent was not possible because majority of women required interpreters. The Hellenic Action for Human Rights reports that none of the women had interpreters offered. Some had brought their own from their camps; however, their interpreters were not allowed to be in the delivery rooms with the patient [45]. While there was inadequate communication processes for consent, the same may also be true for all obstetric care and postpartum instructions within public hospitals. Women often left the hospital unsure of what care they did or did not receive and did not know what to do to continue to medically treat them when discharged from the hospital. Wound breakdowns from CS have been reported and refugee women were either not aware that incisional stitches needed to be removed at a later date or were aware but medical care was too far away [45].

\section{Discussion}

Women displaced into refugee camps, non-camp host communities, and internally displaced within their own countries are at increased risk for poor perinatal outcomes. This risk of poor outcomes particularly mental health, maternal mortality, preterm birth and congenital anomalies persists for women migrants in new host communities. The reasons are complex and include obstruction of access of care by multiple barriers: structural, organizational, social, personal and cultural. There are complex obstetric issues, sexual assault, offspring mortality, unwanted pregnancy, poverty, social isolation and experiences of racism, prejudice and stereotyping within perinatal healthcare [16]. Depending on the particular environment, pregnant refugee women either have limited care or are subjected to increasing operative obstetrical care. 
Refugees are some of the world's most vulnerable populations and this is especially true in regards to their medical care [51]. Often times, this care is absent and when provided has to go through additional hurdles of cultural and language barriers. Although Greece was used as an example above, they are not alone in treating refugee populations. Many countries are currently in the same situation.

Since 1995, the Inter-agency Working Group (IAWG) on Reproductive Health in Crises has been working to develop and expand reproductive health services during crises situations [52] [53]. The set of healthcare recommendations are called Minimum Initial Service Package (MISP) for Reproductive Health in crisis situations [54]. To prevent unnecessary maternal and newborn infections and deaths, skilled birth attendants should be present at all births and basic supplies-such as soap, plastic sheets, clean string and clean razor blades-must be available [7]. Facilities are rated by capacity as either providing basic emergency obstetric and neonatal care (EmONC) which occurs in health center or comprehensive EmONC which occur in hospitals [55]. The Center for Disease Control in conjunction with USAID has published a reproductive health assessment toolkit for conflict-affected women that provide guidance on health infrastructure development, procedure checklists, and data collection [56].

A big strategy for improving EmONC is the development of training programs and adding in-service training. Another strategy is coordinating with NGOs such as Médecins Sans Frontières (MSF) for ambulance services. In Afghanistan, a comprehensive national midwifery education system has improved rural women's access to skilled care and reduced maternal deaths [57]. The Reproductive Health Response in Conflict (RHRC) Consortium with support of the Averting Maternal Death and Disability (AMDD) programme, has worked in 12 conflict-affected settings in nine countries and reported on their experience from 2000-2005 [58]. They reported reduction maternal morbidity and mortality in select conflict-affected settings by improving the availability of EmOC.

Although there are many times when caesareans are indicated for both maternal and fetal reasons, there has been a worldwide increase to caesarean rates. Data from the Euro-Peristat study has identified a range of Caesarean section rates in Europe from a low of 14.8\% in Iceland to a high of 52.5\% in Cyprus [59]. Absolute CS rates for refugee and migrant populations through-out Europe are unknown but are thought to be higher than the national averages [32] [33].

With the current migrant and refugee crisis, vulnerable populations are being subjected to enter a medical system where due to complex factors including their poor health and language barriers and stresses on the existing health infrastructure: limited providers, limited time per patient; lead to expedient obstetrical solutions such as an increase in caesarean sections.

Caesarean section has increased risk of hemorrhage, endometritis, wound complications, injury to pelvic organs and thromboembolic disorders. The Nationwide Inpatient Sample noted that nearly 76 in every 1000 caesarean delive- 
ries had at least one of twelve complications [60]. Within the United States, nearly $6 \%$ of primary caesarean sections were complicated by endometritis, $1 \%$ $2 \%$ had wound complications, $2 \%-4 \%$ required a blood transfusion, and $1 \%$ had a surgical injury to pelvic organs [61]. Although maternal mortality from caesarean section is low in the United States, it is estimated that nearly $0.2 \%$ $0.6 \%$ deaths occur per 100,000 caesarean deliveries [62]. Psychologically, it has also been noted that after caesarean section women express strong feelings of loss, anger, and failure-even without the stresses of living within a refugee camp [63].

Postpartum care within refugee camps can be widely variable depending on the location of the camp and possible proximity of clinics [64]. What is known though, is that the current refugee and migrant situation is almost unprecedented with the number of refugees that are in southern Europe, thus resources are minimal. Female refugees are especially vulnerable and potentially traumatized by gender-based violence [46]. With these limited resources it is much harder to appropriately diagnose and treat wound infections that may occur after hospital discharge [65]. As noted above, many patients live far from medical facilities and are unable to return to the hospital for suture removal and have had wound breakdowns as a result.

Refugee and migrant populations are especially prone to possible relocation without notice [66]. While this would be difficult during any type of postpartum care, when a patient is also recently postoperative they are placed at a higher risk of postsurgical complications. Travel with long periods of immobility (by train, air or boat) makes post caesarean section mothers at a higher risk for possible thromboembolic events. Simultaneously, patients who have no access to such modes of travel and are traveling by foot can possibly disturb their incisions. They also have increased environmental exposure to possible pathogens leaving them at increased risk of having surgical site infections. Migration also limits postpartum care in general for these patients, as health services are often limited during travels.

\section{Recommendations}

Table 3 summarizes recommendations for optimal obstetrical care. Physician shortage and role of midlevel providers: Many systems that heavily rely on caesarean birth are also physician centered for care. Physicians are vital within obstetric care; however, many of these institutions could also use midlevel providers to help ease the burden of care. Midwives and other appropriately licensed midlevel providers could be utilized to aide in antenatal care and vaginal deliveries. Increased training should focus on midwives and women's health care providers engaging in care for women and children in complex humanitarian emergencies [67].

Informed consent: Informed consent remains a basic tenet of medical care. A caesarean section may not be desired, but at times is necessary. Within these situations, providers should attempt to explain the situation. When language 
Table 3. Tools for obstetrical care.

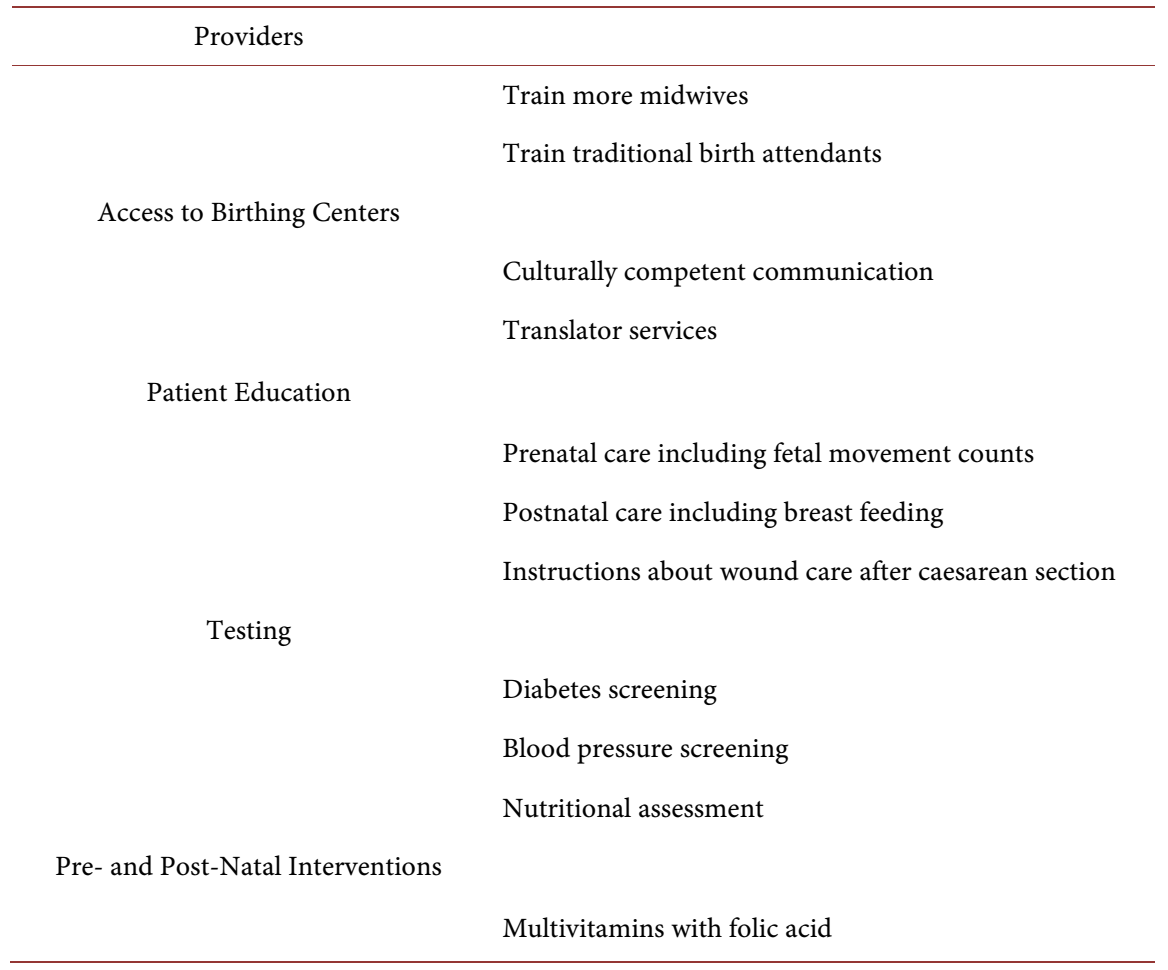

barriers persist, the help of interpreters should be enlisted. If hospitals do not have such resources, refugee camps should be made aware of these institutions and attempt to bring a member from their camp that may be able to help with translation. Although live translators are ideal, interpreter services can be obtained via phone and video. Institutions that are near refugee camps can also preprint possible consents in various languages that detail possible medical situations. When patients are informed, they are empowered and possible traumatic situations can be avoided. Finally, refugees need advocates to be sure consent is truly informed and not coerced [68].

Global awareness: As much as countries are nationally responsible for appropriate medical care, international associations should step in, especially when resources are limited. Greece is currently undergoing an economic struggle and with it is struggling with a physician shortage. This shortage impacts all of the country's residents, regardless of citizenship. Humanitarian assistance for refugees and internally displaced populations requires particular attention to the common issues affecting morbidity and mortality in women and infants. Monitoring and data collection to prospectively understand patterns of obstetrical care and modes of delivery will guide training and provide oversight on the appropriate use of caesarean sections in vulnerable refugee populations [4] [12].

\section{Conflicts of Interest}

The authors declare no conflicts of interest regarding the publication of this paper. 


\section{References}

[1] UNHCR (2017) United Nations High Commission for Refugees: Global Trends Report 2017.

https://www.unhcr.org/en-us/statistics/unhcrstats/5b27be547/unhcr-global-trends2017.html

[2] Ivanova, O., Rai, M. and Kemigisha, E. (2018) A Systematic Review of Sexual and Reproductive Health Knowledge, Experiences and Access to Services among Refugee, Migrant and Displaced Girls and Young Women in Africa. International Journal of Environmental Research and Public Health, 15, 1583.

https://doi.org/10.3390/ijerph15081583

[3] Bickler, S.N., Weiser, T.G., Kassebaum, N., Higashi, H., Chang, D.C., Barendregt, J.J., Noormahomed, E.V. and Vos, T. (2015) Chapter 2 Global Burden of Surgical Conditions. In: Debas, H.T., Donkor, P., Gawande, A., Jamison, D.T., Kruk, M.E. and Mock, C.N., Eds., Essential Surgery: Disease Control Priorities, 3rd Edition, The International Bank for Reconstruction and Development, The World Bank, Washington DC, 19-40.

[4] Betran, A.P., Torloni, M.R., Zhang, J.J., Gülmezoglu, A.M. and WHO Working Group on Caesarean Section (2015) WHO Statement on Caesarean Section Rates. BJOG: An International Journal of Obstetrics and Gynaecology, 123, 667-670. https://doi.org/10.1111/1471-0528.13526

[5] Montoya-Williams, D., Lemas, D.J., Spiryda, L., Patel, K., Neu, J. and Carson, T.L. (2017) What Are Optimal Cesarean Section Rates in the U.S. and How Do We Get There? A Review of Evidence-Based Recommendations and Interventions. Journal of Women's Health (Larchmt), 26, 1285-1291. https://doi.org/10.1089/jwh.2016.6188

[6] UN Women (2017) Facts and Figures Humanitarian Action. http://www.unwomen.org/en/what-we-do/humanitarian-action/facts-and-figures

[7] Women's Refugee Commission (2019) Sexual and Reproductive Health. https://www.womensrefugeecommission.org/srh

[8] UNHCR (2017) United Nations High Commissioner for Refugees (UNHCR), Desperate Journeys.

http://www.unhcr.org/news/updates/2017/2/58b449f54/desperate-journeys-refugees -migrantsentering-crossing-europe-via-mediterranean.html

[9] IAWG (2004) Inter-Agency Working Group on Reproductive Health in Refugee Situations: Report of an Inter-Agency Global Evaluation of Reproductive Health Services for Refugees and Internally Displaced Persons. Geneva. https://www.unhcr.org/41c846f44.pdf

[10] Urdal, H. and Che, P.C. (2013) War and Gender Inequalities in Health: The Impact of Armed Conflict on Fertility and Maternal Mortality. Journal of International Interactions, 39, 489-510. https://doi.org/10.1080/03050629.2013.805133

[11] Pedersen, G.S., Grøntved, A., Mortensen, L.H., Andersen, A.-M.N. and Rich-Edwards, J. (2014) Maternal Mortality among Migrants in Western Europe: A Meta-Analysis. Maternal and Child Health Journal, 18 1628-1638. https://doi.org/10.1007/s10995-013-1403-x

[12] Pyone, T., Dickinson, F., Kerr, R., Boschi-Pinto, C., Mathai, M. and van den Broek, N. (2015) Data Collection Tools for Maternal and Child Health in Humanitarian Emergencies: A Systematic Review. Bulletin of the World Health Organization, 93, 648-658. https://doi.org/10.2471/BLT.14.148429

[13] Casey, S.E. (2015) Evaluations of Reproductive Health Programs in Humanitarian 
Settings: A Systematic Review. Conflict and Health, 9, S1.

https://conflictandhealth.biomedcentral.com/articles/10.1186/1752-1505-9-S1-S1 https://doi.org/10.1186/1752-1505-9-S1-S1

[14] Gissler, M., Alexander, S., MacFarlane, A., Small, R., Stray-Pedersen, B., Zeitlin, J., Zimbeck, M. and Gagnon, A. (2009) Stillbirths and Infant Deaths among Migrants in Industrialized Countries. Acta Obstetrica et Gynecologica Scandinavia, 88, 134-148. https://doi.org/10.1080/00016340802603805

[15] Casey, S.E., Chynoweth, S.K., Cormier, N., Gallagher, M.C. and Wheeler, E.E. (2015) Progress and Gaps in Reproductive Health Services in Three Humanitarian Settings: Mixed-Methods Case Studies. Conflict and Health, 9, S3. https://doi.org/10.1186/1752-1505-9-S1-S3

[16] Heslehurst, N., Brown, H., Pemu, A., Coleman, H. and Rankin, J. (2018) Perinatal Health Outcomes and Care among Asylum Seekers and Refugees: A Systematic Review of Systematic Reviews. BMC Medicine, 16, 89. https://doi.org/10.1186/s12916-018-1064-0

[17] Small, R., Gagnon, A., Gissler, M., Zeitlin, J., Bennis, M., Glazier, R., Haelterman, E., Martens, G., McDermott, S., Urquia, M. and Vangen, S. (2008) Somali Women and Their Pregnancy Outcomes Postmigration: Data from Six Receiving Countries. BJOG, 115, 1630-1640. https://doi.org/10.1111/j.1471-0528.2008.01942.x

[18] Gibson-Helm, M., Teede, H., Block, A., Knight, M., East, C., Wallace, E.M. and Boyle, J. (2014) Maternal Health and Pregnancy Outcomes among Women of Refugee Background from African Countries: A Retrospective, Observational Study in Australia. BMC Pregnancy and Childbirth, 14, 392. https://doi.org/10.1186/s12884-014-0392-0

[19] Zanconato, G., Iacovella, C., Parazzini, F., Bergamini, V. and Franchi, M. (2011) Pregnancy Outcome of Migrant Women Delivering in a Public Institution in Northern Italy. Gynecologic and Obstetric Investigation, 72, 157-162. https://doi.org/10.1159/000328318

[20] Vangen, S., Stoltenberg, C., Skrondal, A., Magnus, P. and Stray-Pedersen, B. (2000) Cesarean Section among Immigrants in Norway. Acta Obstetrica et Gynecologica Scandanavia, 79, 553-558. https://doi.org/10.1080/j.1600-0412.2000.079007553.x

[21] Chi, P.C., Bulage, P., Urdal, H. and Sundby, J. (2015) Barriers in the Delivery of Emergency Obstetric and Neonatal Care in Post-Conflict Africa: Qualitative Case Studies of Burundi and Northern Uganda. PLOS ONE, 10, e0139120.

[22] World Health Organization (WHO) (2019) Maternal Mortality Situation by Country. https://www.who.int/gho/maternal_health/mortality/maternal/en/

[23] Jamieson, D.J., Meikle, S.F., Hillis, S.D., Mtsuko, D., Mawji, S. and Duerr, A. (2000) An Evaluation of Poor Pregnancy Outcomes among Burundian Refugees in Tanzania. JAMA, 283, 397-402. https://doi.org/10.1001/jama.283.3.397

[24] Gibson-Helm, M., Boyle, J., Cheng, I.H., East, C., Knight, M. and Teede, H. (2015) Maternal Health and Pregnancy Outcomes among Women of Refugee Background from Asian Countries. International Journal of Gynaecology \& Obstetrics, 129, 146-151. https://doi.org/10.1016/j.ijgo.2014.10.036

[25] UNHCR United Nations High Commissioner for Refugees (UNHCR), Afghanistan. https://www.unhcr.org/afghanistan.html

[26] Bartlett, L.A., Jamieson, D.J., Kahn, T., Sultana, M., Wilson, H.G. and Duerr, A. (2002) Maternal Mortality among Afghan Refugees in Pakistan, 1999-2000. The Lancet, 359, 643-649. https://doi.org/10.1016/S0140-6736(02)07808-X

[27] Purdin, S., Khan, T. and Saucier, R. (2009) Reducing Maternal Mortality among 
Afghan Refugees in Pakistan. International Journal of Gynaecology and Obstetrics, 105, 82-85. https://doi.org/10.1016/j.ijgo.2008.12.021

[28] Mercy Corps. (2019) Rohingya Refugee Crisis: Quick Facts. https://www.mercycorps.org/articles/bangladesh/rohingya-refugee-crisis-quick-facts

[29] Mullany, L.C., Lee, T.J., Yone, L., Lee, C.I., Teela, K.C., Paw, P., Shwe Oo, E.K., Maung, C., Kuiper, H., Masenior, N.F. and Beyrer, C. (2010) Impact of Community-Based Maternal Health Workers on Coverage of Essential Maternal Health Interventions among Internally Displaced Communities in Eastern Burma: The MOM Project. The PLoS Medicine, 7, e1000317.

[30] Van Damme, W., De Brouwere, V., Boelaert, M. and Van Lerberghe, W. (1998) Effects of a Refugee Assistance Programme on Host Population in Guinea as Measured by Obstetric Interventions. The Lancet, 351, 1609-1613.

[31] Tatah, L., Delbiso, T.D., Rodriguez-Llanes, J.M., Gil Cuesta, J. and Guha-Sapir, D. (2016) Impact of Refugees on Local Health Systems: A Difference-in-Differences Analysis in Cameroon. PLoS ONE, 11, e0168820.

https://doi.org/10.1371/journal.pone.0168820

[32] Gagnon, A.J., Zimbeck, M., Zeitlin, J., ROAM Collaboration, Alexander, S., Blondel, B., Buitendijk, S., Desmeules, M., Di Lallo, D., Gagnon, A., Gissler, M., Glazier, R., Heaman, M., Korfker, D., Macfarlane, A., Ng, E., Roth, C., Small, R., Stewart, D., Stray-Pederson, B., Urquia, M., Vangen, S., Zeitlin, J. and Zimbeck, M. (2009) Migration to Western Industrialised Countries and Perinatal Health: A Systematic Review. Social Science and Medicine, 69, 934-946. https://doi.org/10.1016/j.socscimed.2009.06.027

[33] Merry, L., Small, R., Blondel, B. and Gagnon, A.J. (2013) International Migration and Caesarean Birth: A Systematic Review and Meta-Analysis. BMC Pregnancy and Childbirth, 13, 27. https://doi.org/10.1186/1471-2393-13-27

[34] Schillinger, D. and Chen, A.H. (2004) Literacy and Language: Disentangling Measures of Access, Utilization, and Quality. Journal of General Internal Medicine, 19, 288-290. https://doi.org/10.1111/j.1525-1497.2004.40102.x

[35] UNHCR United Nations High Commissioner for Refugees (UNHCR). Refugees and Migrants Sea Arrivals in Europe. https://data2.unhcr.org/ar/documents/download/49921

[36] Kotsiou, O.S., Kotsios, P., Srivastava, D.S., Kotsios, V., Gourgoulianis, K.I. and Exadaktylos, A.K. (2018) Impact of the Refugee Crisis on the Greek Healthcare System: A Long Road to Ithaca. International Journal of Environmental Research and Public Health, 15, 1790. https://doi.org/10.3390/ijerph15081790

[37] Kotsiou, O.S., Srivastava, D.S., Kotsios, P., Exadaktylos, A.K. and Gourgoulianis, K.I. (2018) The Emergency Medical System in Greece: Opening Aeolus' Bag of Winds. International Journal of Environmental Research and Public Health, 15, pii: E745. https://doi.org/10.3390/ijerph15040745

[38] Christodoulou, G.N. and Abou-Saleh, M.T. (2016) Greece and the Refugee Crisis: Mental Health Context. BJPsych International, 13, 89-91. https://doi.org/10.1192/S2056474000001410

[39] Moris, D. and Kousoulis, A. (2017) Refugee Crisis in Greece: Healthcare and Integration as Current Challenges. Perspectives in Public Health, 137, 309-310. https://doi.org/10.1177/1757913917726019

[40] De Paoli, L. (2018) Access to Health Services for the Refugee Community in Greece: Lessons Learned. Public Health, 157, 104-106. https://doi.org/10.1016/j.puhe.2018.01.011 
[41] Ekathimerini.com (2017) Six in 10 Births in Greece Are via C-Section Kathimerini. http://www.ekathimerini.com/204289/article/ekathimerini/news/six-in-10-births-in -greece-are-via-c-section

[42] Tampakoudis, P., Assimakopoulos, E., Grimbizis, G., Zafrakas, M., Tampakoudis, G., Mantalenakis, S. and Bontis, J. (2004) Cesarean Section Rates and Indications in Greece: Data from a 24-Year Period in a Teaching Hospital. Clinical and Experimental Obstetrics \& Gynecology, 31, 289-292.

[43] Vlachos, G., Tsikouras, P., Manav, B., Trypsianis, G., Liberis, V., Karpathios, S. and Galazios, G. (2015) The Effect of the Use of a New Type of Partogram on the Cesarean Section Rates. Journal of the Turkish German Gynecological Association, 16, 145-148. https://doi.org/10.5152/jtgga.2015.15074

[44] Avramidou, I.A. (2013) The Maternity System and the Birth Choices of Women in Greece 2013. Birthrights in Greece.

http://forbirth.blogspot.com/2013/11/the-maternity-system-and-birth-choices.html

[45] Hellenic Action for Human Rights (2017) Pleiades Report on Refugee Mothers-Preliminary Findings on Antenatal, Perinatal and Postnatal Care of Refugees in Greece. Survey on Maternity Practices in Greece.

http://hellenicaction.blogspot.com/2016/10/hric-europe-summit-report-greece.html

[46] Grotti, V., Malakasis, C., Quagliariello, C. and Sahraoui, N. (2018) Shifting Vulnerabilities: Gender and Reproductive Care on the Migrant Trail to Europe. Comparative Migration Studies, 6, 23. https://doi.org/10.1186/s40878-018-0089-z

[47] The Guardian (2017) Greek Hospitals Deepen Trauma for Refugee Women Giving Birth.

https://www.theguardian.com/global-development-professionals-network/2016/dec /19/greek-hospitals-deepen-trauma-for-refugee-women-giving-birth

[48] Chrysopoulos, P. (2016) Doctors Continue to Emigrate Abroad, Despite Shortages in Greece.greekreporter.com.

http://greece.greekreporter.com/2016/11/06/doctors-continue-to-emigrate-abroaddespite-shortages-in-greece/

[49] Rachiotis, G., Kourousis, C., Kamilaraki, M., Symvoulakis, E.K., Dounias, G. and Hadjichristodoulou, C. (2014) Medical Supplies Shortages and Burnout among Greek Health Care Workers during Economic Crisis: A Pilot Study. International Journal of Medical Sciences, 11, 442-447. https://doi.org/10.7150/ijms.7933

[50] World Health Organization (2015) Core Health Indicators WHO European Region. http://www.euro.who.int/_data/assets/pdf_file/0019/290440/Core-Health-Indicato rs-European-2015-human-resources-health.pdf?ua=1

[51] Cohen, S.A. (2009) The Reproductive Health Needs of Refugees and Displaced People: An Opening for Renewed US Leadership. Guttmacher Policy Review, 12, 15-19.

[52] Women's Refugee Commission (2011) Minimum Initial Service Package (MISP) for Reproductive Health in Crisis Situations. New York.

https://www.womensrefugeecommission.org/resources/download/575

[53] (IAWG) Inter-Agency Working Group on Reproductive Health in Crises (2010) Inter-Agency Field Manual on Reproductive Health in Humanitarian Settings. Geneva.

https://www.who.int/reproductivehealth/publications/emergencies/field_manual/en/

[54] UNFPA (2010) Inter-Agency Field Manual on Reproductive Health in Humanitarian Settings: 2010 Revision for Field Review. Inter-Agency Working Group (IAWG) on Reproductive Health in Crises, New York, 1-217. 
[55] AMDD Averting Maternal Death and Disability (2013) Emergency Obstetric and Newborn Care: Life Saving Services for Women and Babies during Childbirth. AMDD Program Briefs.

https://www.mailman.columbia.edu/research/averting-maternal-death-and-disabilit y-amdd/toolkit

[56] CDC (2007) Reproductive Health Assessment Toolkit for Conflict-Affected Women. Division of Reproductive Health, National Center for Chronic Disease Prevention and Health Promotion, Coordinating Center for Health Promotion, Centers for Disease Control and Prevention, Department of Health and Human Services, Atlanta. http://www.cdc.gov/reproductivehealth/Refugee/

[57] Turkmani, S., Currie, S., Mungia, J., Assefi, N., Javed Rahmanzai, A., Azfar, P., et al. (2013) Midwives Are the Backbone of Our Health System: Lessons from Afghanistan to Guide Expansion of Midwifery in Challenging Settings. Midwifery, 29, 1166-1172.

[58] Krause, S.K., Meyers, J.L. and Friedlander, E. (2006) Improving the Availability of Emergency Obstetric Care in Conflict-Affected Settings. Global Public Health, 1, 205-228. https://doi.org/10.1080/17441690600679939

[59] Macfarlane, A.J., Blondel, B., Mohangoo, A.D., Cuttini, M., Nijhuis, J., Novak, Z., Ólafsdóttir, H.S., Zeitlin, J. and Euro-Peristat Scientific Committee (2016) Wide Differences in Mode of Delivery within Europe: Risk-Stratified Analyses of Aggregated Routine Data from the Euro-Peristat Study. BJOG, 123, 559-568. https://doi.org/10.1111/1471-0528.13284

[60] Creanga, A.A., Bateman, B.T., Butwick, A.J., Raleigh, L., Maeda, A., Kuklina, E. and Callaghan, W.M. (2015) Morbidity Associated with Cesarean Delivery in the United States: Is Placenta Accreta an Increasingly Important Contributor? American Journal Obstetrics Gynecology, 213, 384.e1-e11.

[61] Hammad, I.A., Chauhan, S.P., Magann, E.F. and Abuhamad, A.Z. (2014) Peripartum Complications with Cesarean Delivery: A Review of Maternal-Fetal Medicine Units Network Publications. Journal of Maternal-Fetal Neonatal Medicine, 27, 463-474. https://doi.org/10.3109/14767058.2013.818970

[62] Clark, S.L., Christmas, J.T., Frye, D.R., Meyers, J.A. and Perlin, J.B. (2014) Maternal Mortality in the United States: Predictability and the Impact of Protocols on Fatal Postcesarean Pulmonary Embolism and Hypertension-Related Intracranial Hemorrhage. American Journal Obstetrics and Gynecology, 211, 32.e1-9. https://doi.org/10.1097/01.ogx.0000458788.47940.2f

[63] Clement, S. (2001) Psychological Aspects of Caesarean Section. Best Practice \& Research. Clinical Obstetrics \& Gynaecology, 15, 109-126.

[64] Khan, A. and DeYoung, S.E. (2018) Maternal Health Services for Refugee Populations: Exploration of Best Practices. Global Public Health, 6, 1-13.

[65] Olsen, M.A., Butler, A.M., Willers, D.M., Devkota, P., Gross, G.A. and Fraser, V.J. (2008) Risk Factors for Surgical Site Infection after Low Transverse Cesarean Section. Infection Control and Hospital Epidemiology, 29, 477-484. https://doi.org/10.1086/587810

[66] Bozorgmehr, K., Szecsenyi, J., Stock, C. and Razum, O. (2016) Europe's Response to the Refugee Crisis: Why Relocation Quotas Will Fail to Achieve "Fairness" from a Health Perspective. European Journal of Public Health, 26, 5-6. https://doi.org/10.1093/eurpub/ckv246

[67] Al Gasseer, N., Dresden, E., Keeney, G.B. and Warren, N. (2004) Status of Women and Infants in Complex Humanitarian Emergencies. Journal of Midwifery and 
Women's Health, 49, 7-13. https://doi.org/10.1016/j.jmwh.2004.05.001

[68] Malmqvist, E., Furberg, E. and Sandman, L. (2017) Ethical Aspects of Medical Age Assessment in the Asylum Process: A Swedish Perspective. International Journal of Legal Medicine, 132, 815-823. https://doi.org/10.1007/s00414-017-1730-3 